\title{
VIGOREXIA: INFLUÊNCIA DOS PADRÕES ESTÉTICOS CULTURAIS E OBSESSÃO PELO CORPO IDEAL
}

\author{
VIGOREXIA: INFLUENCE OF AESTHETIC CULTURAL PATTERNS AND OBSESSION BY \\ THE IDEAL BODY
}

Thais Lins de Freitas,

Giovanna Botini Zortea,

Valdilene Wagner,

Leonardo Pestillo de Oliveira

\section{RESUMO}

A sociedade exerce pressão sobre como deve ser a estrutura corporal dos indivíduos. A auto percepção do peso pode estar relacionada com a distorção da imagem corporal. Nos homens, a preocupação excessiva com o corpo pode desencadear Transtornos Alimentares, além de um novo transtorno comportamental denominado Vigorexia. Assim, nos anos de 2016 e 2017 buscou-se coletar e agrupar variáveis que indicassem quais implicações à disseminação de um padrão de beleza superestimado socialmente tem gerado na percepção e conduta dos indivíduos. Para isso, a pesquisa contou com a colaboração de quatro indivíduos, sendo dois destes praticantes de fisiculturismo e outros dois compondo o grupo controle (praticantes de exercício físico a mais de dois anos consecutivos sem qualquer inclinação ou volição pelo fisiculturismo). Nestes indivíduos fora aplicado um questionário semiestruturado de questões abertas e utilizado, posteriormente a análise, como parâmetro de comparação entre os discursos. Por fim, foi possível definir um padrão de comportamento e percepção comum entre os indivíduos acometidos pela Vigorexia, diferenciando a prática física saudável da obsessão pelo corpo perfeito.

PALAVRAS-CHAVE: Atividade física; Padrões de beleza; Vigorexia.

\begin{abstract}
ABSRACT
Society exerts pressure on what the body structure of individuals should be like. Selfperception of weight may be related to distortion of body image. In men, excessive preoccupation with the body can trigger Eating Disorders, in addition to a new behavioral disorder called Vigorexia. Thus, in 2016 and 2017 we sought to collect and group variables that indicate what implications the dissemination of a socially overestimated beauty pattern has generated in individuals' perception and behavior.
\end{abstract}


For this, the research had the collaboration of four individuals, two of these bodybuilding practitioners and two others composing the control group (practicing physical exercise for more than two consecutive years without any inclination or volition by bodybuilding). In these individuals a semistructured questionnaire of open questions was applied and used, later the analysis, as a parameter of comparison between the discourses. Finally, it was possible to define a pattern of behavior and common perception among the individuals affected by Vigorexia, differentiating healthy physical practice from obsession with the perfect body.

key words: Physical activity; Beauty standards; Vigorexia.

\section{INTRODUÇÃO}

A sociedade, em seus aspectos políticos, econômicos e sociais, exerce uma influencia indeclinável na maneira como as pessoas encaram o conceito de "beleza" e constroem sua auto percepção. Camargo, Costa, Uzunian e Viebig (2006), apontam que na Grécia Antiga, em 776 a.C, inaugurando os primeiros Jogos Olímpicos no mundo, sediou o berço da relação entre nutrição e desempenho físico. Neste período, treinadores e atletas buscavam em estratégias alimentares maneiras de aperfeiçoar o rendimento físico. Posteriormente, essa relação passou a estar mais vinculada ao alcance do corpo perfeito do que a busca por um desempenho excelente e uma saúde exemplar.

$\mathrm{Na}$ contemporaneidade, em relação à saúde, Leitão e Nicolaci-da-Costa (2005), desdobram preocupações quanto à influência dos conteúdos virtuais no processo de formação de percepções e condutas dos internautas.

A Vigorexia ou transtorno dismórfico muscular é a distorção da imagem corporal em que a pessoa se percebe como fraco e com pouca massa muscular mesmo que esteja visivelmente forte e musculoso (chegando a ser, na maioria dos casos, exagerado). Para o alcance do corpo venerado, o atleta faz uso de suplementos alimentares, esteróides e anabolizantes aliados a dietas hipercalóricas e atividades físicas em excesso (MELIN e ARAÚJO, 2002).

Alonso (2006), afirma que indivíduos vigoxicos são comumente acometidos por algumas comorbidades, como: depressão, ansiedade, isolamento social, mudanças metabólicas (que afetam, sobretudo, o fígado e o sistema cardiovascular), desordem nos níveis de colesterol, diminuição do centro respiratório, disfunção 
erétil, hipertrofia prostática (aumento da glândula da próstata), hipogonadismo (deficiência funcionar das gônodas que pode acarretar retardamento do crescimento e do desenvolvimento sexual) e ginecomastia (aumento do volume das mamas no homem). Além disso, Assunção (2002) continua a descrever os comprometimentos, elencando: insônia, falta de apetite, irritabilidade, desinteresse sexual, fraqueza, cansaço constante, dificuldade de concentração, problemas físicos e estéticos como: desproporção displásica, irregularidade entre o tamanho do corpo e da cabeça, problemas ósseos e articulares devido ao peso excessivo, falta de agilidade e encurtamento de músculos e tendões.

A nomenclatura Anorexia Nervosa Reversa, que para alguns autores pode ser empregada como sinônimo de Vigorexia, não será adotada neste trabalho, uma vez que, indivíduos portadores de Dismorfia Muscular (Vigorexia) não possuem um distúrbio alimentar, mas são dotados de uma alteração na percepção de seus corpos e obsessão a respeito de sua musculatura (ARBINAGA e CARACUEL, 2003). Por outro lado, a adoção da terminologia Vigorexia/Dismorfia Muscular referindo-se ao distúrbio na percepção e distorção da imagem corporal pode ser reforçada pelo próprio discurso de autodescrição dos indivíduos vigorexicos que percorrem adjetivos como: "fracos", "pequenos", "franzinos", "magros" e com "pouca massa muscular", quando, ao contrário disso, esta população possui desenvolvimento muscular extremamente acentuado.

A Vigorexia foi recentemente incluída no novo manual de psiquiatria americano (DSM-V, 2014) e classificada como um subtipo do Transtorno Dismórfico Corporal (TDC), um problema de saúde mental relacionado à imagem corporal. Segundo Camargo, Costa, Uzunian e Viebig (2006), essa patologia caracteriza-se pela prática excessiva de exercícios físicos, obsessiva preocupação com o corpo e adoção de práticas alimentares não convencionais. Alonso (2005) destaca que a prevalência de Vigorexicos permanece na categoria masculina, na faixa etária entre os 18 e 35 anos.

Existem poucos estudos voltados para a caracterização e identificação adequada de indivíduos acometidos pela Vigorexia. De maneira geral, os vigorexicos são passados despercebidos ou notados como pessoas motivadas a obter saúde. Por isso, é de extrema relevância incitar atenção para este grupo de pessoas que estão cegamente se expondo ao risco de desenvolver o Transtorno Dismórfico 
Muscular; ao passo que, se submetem ao anseio da aquisição do corpo perfeito ao adotarem práticas físicas e alimentares obsessivas.

Os profissionais da área da saúde - nutricionistas, psicólogos médicos e profissionais de educação física - necessitam de amplo domínio quanto à abordagem, identificação e tratamento de indivíduos com Vigorexia. Pesquisas na área podem ser convertidas em ferramentas de conscientização, a fim de evitar ou minimizar a ocorrência do Transtorno. Garantir o bem estar físico e mental com base em um cardápio adaptado, hábitos equilibrados, tratamento médico especializado e treinos moderados é fundamental para a promoção da saúde da população.

Neste sentido, esta pesquisa centrou-se em investigar a interferência da mídia na percepção e comportamento do indivíduo acometido por Vigorexia, verificando e circunscrevendo o padrão de beleza superestimado e disseminado pelos meios de comunicação. Além disso, buscou descrever o modelo de prática física e hábito alimentar reconhecido popularmente como satisfatório na atualidade, atentando-se as implicações do modelo estético cultural no cotidiano do indivíduo que emite comportamentos obsessivos em relação ao alcance do corpo midiaticamente perfeito. Por fim, apontar variáveis que discriminam as fronteiras entre a prática saudável de exercícios físicos e a busca obsessiva por um corpo perfeito convertemse em importantes instrumentos de promoção da saúde.

\section{MATERIAL E MÉTODOS}

A metodologia descrita a seguir relaciona-se a primeira parte deste estudo: revisar sistematicamente as pesquisas realizadas sobre a Vigorexia que conta com apontamentos acerca da relação entre a prática de atividade física excessiva e a absorção dos padrões sociais de beleza.

A segunda parte trata-se de uma pesquisa de caráter exploratório com análise qualitativa. Para tanto, foram selecionados quatro sujeitos do sexo masculino, que obedecia a faixa etária dos 18 anos aos 30 anos de idade. Como fator de inclusão, os sujeitos deveriam, necessariamente, praticar atividade física regularmente há mais de dois anos, dois desses sujeitos compuseram o grupo controle, caracterizados pelos indivíduos que se exercitam fisicamente sem acepção em 
desenvolver um corpo excessivamente musculoso, e os outros dois sujeitos eram atletas fisiculturistas no período em que a pesquisa foi desenvolvida.

Após a seleção populacional, foram especificados para os sujeitos todos os objetivos da pesquisa e ressaltado o caráter sigiloso da mesma, explicando que em momento algum haveria identificação do entrevistado. Foi esclarecido que a coleta de dados ocorreria em apenas um encontro. Após obter conhecimento claro sobre o conteúdo do questionário, o sujeito assinou um termo de consentimento livre e esclarecido, validando sua concordância com a pesquisa. O questionário destinado a coleta de dados foi respondido pelos sujeitos da pesquisa de forma individual, em uma Universidade de Ensino Superior de Maringá.

A coleta dos dados foi realizada por meio de uma entrevista semiestruturada, com 20 questões abertas, no qual as mesmas foram formuladas com o intuito de obter informações acerca dos hábitos alimentares do sujeito, modelos de práticas físicas, concepção de beleza, influência dos padrões sociais na percepção e conduta referente à saúde física.

Os dados foram analisados baseando-se em pesquisas a respeito do Transtorno da Vigorexia. A partir da comparação dos dados entre o grupo controle e - grupo experimental, foi possível indicar, ressaltar e refutar variáveis que distinguem uma prática saudável e um hábito inclinado à patologia, ressaltando a necessidade de mais estudos na área.

\section{RESULTADOS E DISCUSSÃO}

O conceito atribuído a beleza sofreu diversas transformações no decorrer da história da humanidade. Estes conceitos sempre ditaram diferentes formas de perceber e manipular o corpo, objetivando uma imagem corporal estipulada e venerada. De acordo com Rodrigues (1975):

A cultura dita normas em relação ao corpo; normas a que o indivíduo tenderá, à custa de castigos e recompensas, a se conformar, até o ponto de estes padrões de comportamento se the apresentarem como tão naturais quanto o desenvolvimento dos seres vivos. (p.45)

Os indivíduos aderem e buscam o modelo estético normatizado culturalmente baseado, quase que integralmente, na irracionalidade. Neste sentido, a economia 
sempre foi um aspecto influente. Hercovici e Bay (1997), apontam que em tempos remotos, nas quais a escassez de alimento era uma realidade típica e recorrente, o padrão de beleza foi atrelado a uma forma robusta que indicava poder e opulência. De maneira oposta, nas épocas em que havia abundancia de alimentos, indivíduos esguios foram representantes de autodisciplina e sucesso. Assim, os modelos de beleza são indicativos sociais e sinalizadores das diferenças entre classes.

Contemporaneamente, a elevação do uso de aparelhos eletrônicos configurou o estilo de vida da sociedade à medida que trouxe a ela uma nova maneira de se organizar, de se comunicar, interagir com o mundo e, ao que fere essa pesquisa, se autoanalisar. Cassimiro e Galdino (2012) defendem que, a tecnologia, escorada nos canais midiáticos, impulsionou a ânsia do homem pela busca da perfeição física. $O$ que era de início, um desejo ingênuo de se enquadrar as expectativas socioculturais, tornou-se um fator determinante no distanciamento do indivíduo daquilo que é próprio de sua natureza, seu biótipo fisiológico. Em suma, submeter-se a uma conduta obsessiva quanto a prática física e alimentar é pré-requisito no alcance do padrão excelente de beleza, em uma sociedade, em que tudo, inclusive o corpo, é uma mercadoria.

Em 1995 e em 1998, nas ilhas de Fiji, foram realizados dois estudos por Becker (2002), com o objetivo de avaliar as consequências no comportamento alimentar de adolescentes expostos a televisão. Os três anos de latência entre os estudos se devem ao fato de que se buscava mensurar, em nível comparativo, a diferença do impacto da mídia durante todo esse período, já que com o decorrer do tempo, o acesso aos canais midiáticos se popularizava. Os resultados mostraram que, em 1998, as variáveis que indicavam a presença do transtorno alimentar foram acentuadamente mais manifestas no comportamento dos participantes do que em 1995. Além disso, a amostra populacional pesquisada demonstrou maior interesse pela perda de peso.

No intuito de avaliar possíveis distorções na imagem corporal e identificar a influência midiática na formação de padrões de beleza, esta pesquisa foi realizada com atletas praticantes de academia, diferenciando entre si pela pretensão ao fisiculturismo. Todos os participantes da pesquisa foram do sexo masculino, com 21 anos de idade e solteiros. Um dos critérios de seleção dos entrevistados foi que estivessem praticando musculação no momento da pesquisa e que, ao mesmo 
tempo, esta fosse uma prática recorrente nos últimos dois anos, sem interrupções. Como forma de facilitar a identificação dos participantes da pesquisa, os mesmos foram nomeados com os termos "F1" (fisiculturista) e PC (pessoa controle). Os dois voluntários praticavam musculação há, mais ou menos, 6 anos e confirmaram o fato de que desde muito pequenos se engajaram em algum tipo de esporte ou atividade física de qualquer modalidade. O participante F1 estava cursando fisioterapia e o PC já era formado e trabalhava como fisioterapeuta no momento da pesquisa. Alguns dados quantitativos serão expostos a seguir a fim de traçar, dentro do possível, o perfil corporal dos participantes: o participante $\mathrm{F} 1$ possui altura de 1,70 $\mathrm{M}$, peso de $98 \mathrm{Kg}$, com percentual de gordura de $12 \%$. Sua aparência física é de uma pessoa excessivamente forte. PC tem 1,78 M de altura, $73 \mathrm{Kg}$ e não possui uma medida concreta do seu percentual de gordura. Aparenta ser uma pessoa forte, tendendo a ser esbelta.

F1 pratica atividade física, no mínimo 6 dias por semana, enquanto PC pratica de 4 a 5 dias por semana. Quando solicitado que os participantes descrevessem um dia da sua semana, F1 respondeu que acorda às $7 \mathrm{~h}$ da manhã, toma seu café da manhã e vai para a faculdade, as $10 \mathrm{~h}$ faz outra refeição e, por volta do 12:30, momento em que chega em casa, almoça. Após a refeição, cochila por 40min e, então, às três horas da tarde se prepara para a academia, fazendo outra refeição e suplementando-se. Após o treino de $1 \mathrm{~h} 30 \mathrm{~min}$, que é dividido em a/b/c/d/e (com 6 exercícios por subgrupo muscular, categoria submáxima) F1 come uma fruta e uma barrinha de proteína. Vale um adendo neste ponto ao que se refere à atividade aeróbica praticada pelo colaborado em um dia da semana, com foco de perde de gordura em seu treino. Além disso, nos finais de semana, não raramente, F1 joga futebol. Às $18 \mathrm{~h}$ o participante janta e às $22 \mathrm{~h}$ ingere o último lanche do dia. Dedicando-se cerca de $8 \mathrm{~h}$ por dia aos cuidados com o seu corpo, incluindo alimentação e atividade física, visto que em uma escala de 0 a 10 , o participante avalia com 9 sua preocupação com o corpo. Por fim, F1 diz que sua estratégia de manutenção de peso visando à competição no fisiculturismo é a ingestão de proteínas, a prática intensiva de exercícios aeróbicos visando à perda de gordura e a utilização de substancias ergogênicas, incluindo suplementos, esteroides e anabolizantes. 
O fisiculturismo exige um ritual obsessivo a ser seguido. A insatisfação corporal promove o comportamento alimentar diferenciado - hipercalórico, com o uso de suplementação, esteróides e anabolizantes - e prática física excessiva. A explanação da rotina de $\mathrm{F} 1$ demonstrou o quanto suas atividades diárias estão voltadas para o cuidado com o corpo e o alcance do biótipo ideal, despendendo grande parte de sua energia diária em prol do que é, hoje, seu principal objetivo de vida. Conforme Cury (2005) defende, existe um padrão de beleza inatingível, maciçamente difundido pela mídia que coloca o indivíduo diante de sua impotência com a impossibilidade biológica de se atingir o modelo almejado. Assim, Andrade e Bosi (2003), complementam afirmando que essa busca alienada rompe com a tênue linha divisória entre o cuidado saudável com o corpo e o sutil movimento de instalação de doenças.

A rotina descrita por $\mathrm{PC}$ foi avaliada com maior flexibilidade e maleabilidade, apontando para o fato de que seu foco de vida não se prende e nem se organiza em torno do alcance do corpo "perfeito". De acordo com Melin e Araújo (2002), o bem estar e satisfação humana exalam saúde quando é advindo, simultaneamente, de fontes diversas, como: esportes, amizades, família, trabalho, estudos, artes e, até mesmo, com o cuidado com o corpo. Contudo, a beleza não deve ocupar papel fundamental para o desenvolvimento da autoestima de um indivíduo, pois, assim, poderá prescrever comportamentos de riscos e levarem a instalação de transtornos.

Quando questionados ao que os motivou a iniciar a atividade física, F1 explicou que havia uma necessidade de corrigir sua postura corporal e, por isso, foi recomendado seu ingresso em alguma modalidade desportiva. Atualmente, a competição é o principal fator que faz F1 permanecer no esporte. A UNIFESP Universidade Estadual de São Paulo, por meio do Departamento de Psiquiatria, publicou um estudo realizado em Minnesota (Estados Unidos) com 1.307 adolescentes e publicado no jornal americano "Pediatrics", em novembro de 2012, revelando que $90 \%$ dos jovens se exercitam apenas para ganhar músculos. Por outro lado, PC buscava aumentar sua qualidade de vida, prevenir lesões, melhorar a aparência, agregar maior reconhecimento profissional (devido a sua profissão estar atrelada ao condicionamento físico) e, por fim, percebia a modalidade como uma forma de descontração. Contemporaneamente, estes continuam sendo seus principais motivadores. 
De acordo com Ballone (2005), na adolescência, período na qual o corpo passa por transformações mais severas, é natural que o individuo passe a ser mais exigente quanto à própria forma física, uma vez que tende a procurar se enquadrar aos estereótipos sociais. Contudo, essa necessidade de adaptação ao padrão estético cultural, quando exagerada e permanente, expõe o jovem ao risco de desenvolver alguns transtornos alimentares, ansiógenos ou de imagem corporal, incluindo a Vigorexia. Portanto, a relevância da identificação precoce da Vigorexia está na possibilidade de evitar o consumo de drogas e restringir comportamentos exagerados e inadequados em virtude do alcance dos resultados superestimados.

Para que as questões sobre a percepção dos colaboradores pudessem ser exploradas com maior profundidade, esta pesquisa contou com a utilização de imagens, nas quais F1 e PC deveriam relatar aquilo que pensavam e sentiam após ver e analisar algumas fotos. Assim, diante da imagem de comidas calóricas, F1 disse que as considera boas, mas que se sentiria culpado caso as comesse. Já PC acredita que essas pessoas têm um pensamento de "gordo", que esse tipo de alimento, apesar da carne, quase não dispõe de proteínas e, devido à quantidade de gordura contida, não valeria apena comê-las. Mesmo assim, ele as come sentindo seu percentual de gordura aumentando, mas experenciando pouca culpa relativo a isso.

O ser humano é pressionado, de diversas formas, a concretizar, no corpo, o ideal cultural pregoado pela sociedade. É coagido ao encontro de determinada representação por castigos (críticas, desprezo e deboche) e gratificações (dinheiro, poder e admiração) (CARRETEIRO, 2005). A culpa, neste sentido, é uma consequência esperada para ocasiões que os indivíduos se expõem ao risco de não se enquadrarem as expectativas de beleza.

Ao ser solicitado que F1 se auto descrevesse, o mesmo o definiu como uma pessoa forte (mas que poderia estar melhor), baixo e bonito. Por outro lado, PC definiu-se como possuidor de uma barriga saliente, peitoral bem apresentável, nariz avantajado, dentes grandes e bonitos, canelas finas, ombros bem mais desenvolvidos do que antes de iniciar na academia, antebraço legal, bíceps e tríceps podendo melhorar e, de modo geral, como uma pessoa bonita. Com esses discursos, verifica-se uma alta exigência de ambos participantes ao que se refere ao alcance e manutenção da aparência física, destacando que, de maneira patológica 
ou não, todos os indivíduos, de alguma forma, se submetem ao padrão estético estipulado socialmente. O sofrimento, obsessão ou (apenas) motivação são consequências possíveis de serem colhidas a partir de então. Castilho (2001), aponta que, por volta dos dois anos de idade, a criança já despende de uma rudimentar percepção sobre si mesmas, pois já é capaz de se reconhecer em frete ao espelho. Com o passar do tempo, o corpo converte-se em um elemento importante na formação da identidade. A percepção sobre si, a partir de então, estará diretamente relacionada aos introjetos culturais daquilo que é belo e atraente, ou seja, seu modo de pensar sobre sua aparência dependerá do modo como as outras pessoas avaliam o corpo e imagem da criança. O mesmo autor defende que, assim, o individuo assimila, desde muito cedo o estereótipo valorizado socialmente e, mesmo após atingirem o peso ideal sentem insatisfação com suas formas corporais, engajando-se em condutas patológicas.

F1 avalia sua frequência, intensidade e vontade pela prática física como sendo alta chegando a ser excessiva. Por outro lado PC considera esses mesmos aspectos como moderados pendendo a alto, mas sendo o suficiente e, por isso, sem muita volição a aumentar. Em situações nas quais os colaboradores precisam exporse, PC relata que ao mesmo tempo em que se sente bonito, considera sua barriga avantajada, sentindo um misto de vergonha e orgulho. Por outro lado, F1 diz que, acostumou-se a situações em que seu corpo é posto em evidencia e observação, portanto, atualmente, não sente mais receio em expô-lo.

No mundo contemporâneo, o corpo se tornou um dos valores mais importantes da sociedade. Diante do culto ao corpo, cunhado por Castilho (2001), sentir-se inadequado as exigências sociais é a realidade para a maior parte da população que não obedece rigorosamente ao padrão estético. Dietas saudáveis e exercícios moderados não são suficientes para a adesão do modelo, impulsionando os indivíduos a aquisição de práticas impróprias para o controle de peso.

Ao se depararem com a imagem de pessoas abaixo do peso, o participante PC diz que a considera feia, pois ela é muito magra, enquanto F1 sente nostalgia de uma época em que ele também era muito magro e afirma que não voltaria atrás. Quando analisam a imagem de uma pessoa musculosa, F1 diz que são corpos bons e fortes (principalmente a do homem) e sente motivação para continuar treinando. Já PC descreve o corpo da mulher como sendo bonito e do homem como exagerado, 
mas que de maneira geral, são corpos saudáveis e pessoas bem cuidadas e disciplinadas que investem em alimentação e suplementação, sentindo admiração. Quando mostrado a imagem de comidas saudáveis, F1 diz lembrar-se de dietas e que esse tipo de alimentação seria recomendável para todas as pessoas, que assim como ele, deveriam sentir prazer ao submeter-se a dietas. PC diz que sente fome ao apreciar esse tipo de refeição, uma vez que a considera uma "delícia".

Morgan, Vecchiatti e Negrão (2002), destacam que o padrão sociocultural imposto para o sexo masculino é do corpo forte e definido. A partir disto, dietas e comportamentos de risco são adotados como medidas de alcance do modelo de beleza, considerando o fato de que a gordura é inadmissível. Em um estudo realizado por Fernandes (2007) com estudantes de 6 a 18 anos de escolas públicas e particulares, verificou-se que $62,2 \%$ dos jovens encontravam-se insatisfeitos com o próprio corpo, embora mais de $80 \%$ do total estivessem dentro do peso normal.

Diante da imagem de pessoas acima do peso, o participante PC a descreve como sendo "feias" e que considera intrigante elas conseguirem se achar bonitas mesmo nesta condição. Apesar disto, sente neutralidade, pois desde que ele mesmo (PC) não esteja acima do peso, isso não Ihe afeta em nada. Por outro lado, F1 diz que é evidente o fato dessas pessoas estarem acima do peso e que isso pressupõe a ausência de saúde. Contudo, elas aparentam sentir-se bem nas fotos, portanto, sua opinião (F1) é dispensável.

É contraditório pensar que em um mundo em que há excessiva oferta de alimentos industrializados, hipercalóricos e hiperpalatáveis, se exijam modelos corporais de baixo peso e de zero gordura. Um dos principais elementos sociais propiciadores da inclusão social é o alimento, que perpassa e atravessa todas as relações pessoais. Afinal, quem nunca pensou em encontrar um amigo e, logo em seguida, planejou o cardápio do dia? Mas, quando este alimento é investido de atributos nefastos ao organismo, há um desarranjo em toda a cadeia biológica da população. Portanto, o equivoco não está, prevalentemente, no ato de comer, mas no que, atualmente, se distribui e se valoriza na mesa. $O$ alimento revestido de praticidade imediata, por sua facilidade e rapidez de preparo, promove a satisfação momentânea, rodeada de culpa e malefícios biológicos posteriores. As indústrias de alimentos e de estética, com certeza, se beneficiam desse paradoxo, uma vez que ordenam a população a desejos - ingerir tudo o que é apetitoso aos olhos - e 
objetivos - manter um corpo atraente aos espectadores - contrários entre si. Por fim, colocam o individuo em um ciclo vicioso de cobiça pelo alimento, seguida de culpa pela ingestão e busca de reparação diante do aumento de peso.

Dessa forma, variáveis como: influencia da mídia, internalização da forma corporal ideal, baixa autoestima, insatisfação com corpo, falta de controle da própria saúde, perfeccionismo e distorção da percepção da imagem corporal estão de, alguma forma, presentes no cotidiano de toda a sociedade. Esses elementos predizem condutas e conceitos discriminatórios e preconceituosos, que se não forem, cautelosamente, revistos, continuarão promovendo hábitos patológicos em nível biológico, psicológico e social. O objetivo desta pesquisa não foi o de atrelar o esporte do fisiculturismo a qualquer tipo de doença que possa ser desenvolvida, incluindo a Vigorexia. Alias este esporte está longe de ser utilizado como critério de avaliação da presença ou não da doença referida. O cerne do estudo concentra-se em revelar a forma como os ditames culturais estão entrelaçados na subjetividade das pessoas, de maneira tão intrínsecas e irreversíveis, que são tomadas como naturais. Hábitos físicos e alimentares saudáveis estão encobrindo uma série de pensamentos irracionais difundidos indiscriminadamente, a favor da indústria e do mercado. Percepções equivocadas, condutas obsessivas e valores hostilizados são apenas alguns dos sintomas da benevolência social diante do padrão estético imposto. Portanto, o que difere o Vigorexico do restante da sociedade é o grau e intensidade pela qual estes preceitos mobilizam o individuo em nível psicológico e comportamental, uma vez que, irrefutavelmente, as variáveis discutidas, próprias da patologia, influenciam a toda população.

\section{CONCLUSÃO}

Contemporaneamente, o padrão de beleza superestimado e disseminado pelos meios de comunicação é o do corpo musculoso, atlético e sem gordura. Acoplado a este padrão, modelos de prática física e hábitos alimentares foram configurados e reconhecidos popularmente como satisfatório. Contudo, cotidianamente, ainda não foi possível mensurar as fronteiras entre a prática saudável de exercícios físicos e a busca obsessiva por um corpo perfeito. Assim, de 
forma utópica, um ideal físico é disseminado e, ao ocultar sua face inalcançável, conduz os indivíduos a recorrerem a práticas não saudáveis no intuito de obter o resultado desejado. Não se enquadrar ao padrão, mesmo diante de desenfreados esforços, gera frustração, impotência, ansiedade e mais obsessão por atingi-lo.

Culturalmente, o homem tem dificuldade de expressar seus sentimentos, angústias e indecisões. Esses aspectos dificultam a prevenção e diagnóstico. Os homens que procuram auxílio médico e/ou psicológico, de maneira geral, já se encontram em estados avançados de suas patologias, dificultando ainda mais o tratamento. Além disso, a procura de tratamento é omitida pelo doente, pois os métodos propostos para este, frequentemente, culminam na perda da massa muscular. Caso o indivíduo faça uso de esteróides anabolizantes, sua interrupção deve ser sugerida imediatamente.

Não há formas padronizadas de tratamento da Vigorexia. Contudo, algumas técnicas já foram desenvolvidas e podem auxiliar o cuidado com o indivíduo assistido. No tratamento psicológico, por exemplo, incluem a identificação de padrões distorcidos de percepção da imagem corporal, identificação de aspectos positivos da aparência física, abordagem e encorajamento de atitudes mais sadias, e confrontação com a aversão de expor o corpo.

Por fim, seria utópico falar de uma sociedade cuja cultura não se inscreva sobre o corpo, mas é urgente pensar em uma sociedade com padrões corporais flexíveis, que privilegia o corpo real, corpo possível, e que esse possa transitar de maneira confortável e com vontade pela vida.

\section{REFERÊNCIAS}

ALONSO C. A. M. Vigorexia> enfermedad o adaptatión. Revista Digital Buenos Aires. V. 11, n. 99. 2005.

ANDRADE, A. e BOSI, M. M. Mídias e subjetividade: impacto no comportamento alimentar feminino. Revista de nutrição, 16(1), 117-125, 2003.

ARBINAGA, F., CARACUEL, J. C. Aproimacion a la dismorfia Muscular. Cadernos de Medicina Psicosomatica y Psiquiatria de Enlace, 65, 07-15. 2003. 
ASSUNÇÃO.S. M. Dismorfia Muscular. Revista Brasileira de Psiquiatria, 24(3), 8084, 2002.

BALLONE, G. J. Vigorexia - Sindrome de Adônis. Portal Psiquiatra Geral, 2002.

Disponível em HTTP://virtualpsy.locaweb.com.br/.

CAMARGO, T. P. P.; COSTA, S. P. V.; UZUNIAN, L. G. e VIEBIG, R. F. Vigorexia: Revisão dos Aspectos Atuais Deste Distúrbio de Imagem Corporal. São Paulo, 2006.

CARRETEIRO, T. A. Corpo e contemporaneidade. Psicologia em revista, 11(17), 6276, 2005.

CASSIMIRO, E. S., GALDINO, F. F. S. As concepções de corpo construídas ao longo da história ocidental: da Grécia Antiga a Contemporaneidade. Revista Eletrônica Print Metávoia, São João del-Rei/MG, n.14, 2012.

CASTILHO, S.M. A imagem corporal. Santo André: ESETec Editoras Associados, 2001.

CURY, A. J. A ditadura da beleza e a revolução das mulheres. Rio de Janeiro:

Sextante, 2005.

DSM-5: AMERICAN PSYCHIATRIC ASSOCIATION. Manual Diagnóstico E Estatístico De Transtornos Mentais. 5. ed. Porto Alegre: Artmed, 2014. 992p.

HERCOVICI, C. e BAY, L. Anorexia nervosa e bulimia nervosa: ameaças a autonomia. Porto Alegre: artes médicas, 1997.

LEITÃO, C. F.; NICOLACI-DA-COSTA, A. M. Impactos da internet sobre pacientes: a visão de psicoterapeutas. Psicologia em Estudo, Maringá, v. 10, n. 3, p.441-450, set./dez, 2005.

MELIN, P. e ARAÚJO, A. M. Transtornos alimentares em homens: Um desafio diagnóstico. Revista brasileira de Psiquiatria, 24(3), 73-76, 2002.

MORGAN, C. M., VECCHUATTI, I. R. e NEGRÃO, A. B. Etiologia dos transtornos alimentares: Aspectos biológicos, psicológicos e socioculturais. Revista Brasileira de Psiquiatria, 24(3), 18-23, 2002.

RODRIGUES, I. C. Tabu do corpo. 2 ed. Rio de Janeiro: Achimé, 1975.

UNIFESP - Universidade Estadual de São Paulo. Adolescentes que malham demais podem ser vítimas de transtorno psiquiátrico. Departamento de

Psiquiatria. Disponível

em: $\leq$ http://www2.unifesp.br/dpsiq/novo/sobre/noticias/exibir/?id=253>. Acesso em: 01 fev. 2017. 